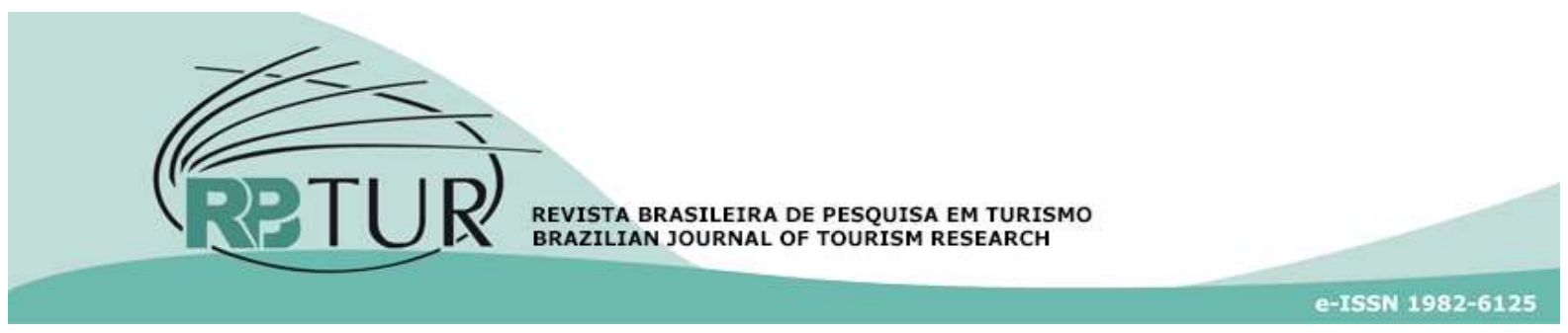

Artigo

DOI: http://dx.doi.org/10.7784/rbtur.v12i3.1354

\title{
O turismo no cenário das mudanças climáticas: impactos, possibilidades e desafios
}

\author{
Tourism in the scenario of climate change: impacts, \\ possibilities, and challenges \\ El turismo en el escenario del cambio climático: impactos, \\ posibilidades y desafíos \\ Isabel Jurema Grimm ${ }^{1}$ \\ Liliane C. S. Alcântara² \\ Carlos Alberto Cioce Sampaio ${ }^{3}$
}

Resumo: O turismo pode ser considerado um setor econômico altamente sensível às mudanças climáticas, e tem contribuído para a emissão de gases de efeito estufa (GEE), uma das causas do aquecimento global. Para mitigar seus impactos negativos, surge a concepção do desenvolvimento do turismo sob a ótica da sustentabilidade que deverá incorporar as externalidades derivadas da mudança climática. Frente a esta realidade, este artigo analisa os impactos, oportunidades e desafios para o desenvolvimento sustentável do turismo no Brasil, a partir dos cenários projetados pela mudança climática global. A metodologia tem abordagem interdisciplinar e sistêmica, de cunho descritivo/analítico, realizada a partir de pesquisa bibliométrica, documental e entrevistas junto aos especialistas na temática do turismo, desenvolvimento e mudanças climáticas. Como resultados temse a construção de cenários prospectivos que mostram possíveis impactos e consequências das mudanças climáticas ao sistema turístico internacional, constituindo-se em informações para fins de mitigação, planejamento de ações de adaptação e minimização de impactos e vulnerabilidades.

Palavras-chave: Impactos Climáticos. Turismo. Adaptação. Mitigação.

\footnotetext{
${ }^{1}$ Instituto Superior de Administração e Economia do Mercosul (ISAE), Curitiba, PR, Brasil.

2 Universidade Federal do Mato Grosso (UFMT), Cuiabá, MT, Brasil.

${ }^{3}$ Fundação Universidade Regional de Blumenau (FURB), Blumenau, SC, Brasil.

* O artigo deriva da tese de doutorado da autora (GRIMM, I.J.). O trabalho de tese foi orientado por (SAMPAIO, C.A.C). A atualização de dados e inserção de novo aporte teórico e revisão de texto foi feito por (ALCANTARA, L.C.S). Assim, salienta-se que a rede atua no sentido da complementariedade, como forma de fomentar e valorizar a pesquisa e o trabalho cooperado.
}

Artigo recebido em: 02/09/2017. Artigo aceito em: 12/06/2018. 
Abstract: Tourism can be considered an economic sector highly sensitive to climate change and has contributed to the emission of greenhouse gases (GHG), one of the causes of global warming. To mitigate its negative impacts, the conception of the development of tourism from the point of view of sustainability emerges, which should incorporate the externalities derived from climate change. Given this reality, this research aims to examine the impacts, opportunities, and challenges for the sustainable development of tourism, based on scenarios projected by the global climate changes. The methodology has a descriptive/analytical, interdisciplinary and systemic approach, based on bibliometric and documentary research, and interviews with specialists in tourism development and climate changes. The results include the construction of prospective scenarios that may show possible impacts and consequences of climate changes on the international tourism system, constituting information for mitigation purposes, planning for adaptation actions, and minimizing impacts and vulnerabilities.

Keywords: Climate Impacts. Tourism. Adaptation. Mitigation.

Resumen: El turismo puede ser considerado un sector económico altamente sensible al cambio climático y ha contribuido a la emisión de gases de efecto invernadero (GEI), una de las causas del calentamiento global. Para mitigar sus impactos negativos, surge la concepción del desarrollo del turismo desde el punto de vista de la sostenibilidad, que debe incorporar las externalidades derivadas del cambio climático. Delante de esta realidad, este artículo analiza los impactos, oportunidades y desafíos para el desarrollo sostenible del turismo, a partir de los escenarios proyectados por el cambio climático global. La metodología tiene un enfoque interdisciplinario y sistémico, de carácter descriptivo/analítico, realizado a partir de investigación bibliometrica, documental y entrevistas junto a los especialistas en la temática del turismo, desarrollo y cambios climáticos. Como resultados se tiene la construcción de escenarios prospectivos que muestran posibles impactos y consecuencias de los cambios climáticos al sistema turístico internacional, constituyéndose en informaciones para fines de mitigación, de planificación de acciones de adaptación y de minimización de estos impactos y vulnerabilidades.

Palabras clave: Impactos Climáticos. Turismo. Adaptación. Mitigación.

\section{INTRODUÇÃO}

Manifestada em diversas escalas de tempo e em parâmetros como precipitações e temperatura, a mudança climática "pode estar sofrendo influência expressiva de processos derivados da natureza, processos estes ainda não convenientemente avaliados" (Conti, 2005, p.71). Entretanto, a partir da revolução industrial houve aumento significativo no uso de carbono (carvão mineral, petróleo e gás natural), que ao serem queimados liberam dióxido de carbono $\left(\mathrm{CO}_{2}\right)$ para a atmosfera aumentando sua propriedade de reter calor. Esta queima de carbono representa, mais de $50 \%$ das emissões de GEE mundiais (Marengo, Mendonça, 2007; IPCC, 2013; Ambrizzi et al.; Pbmc, 2014).
Com papel relevante nesse debate, 0 turismo é um setor afetado pelos efeitos das mudanças do clima, mas que também contribui com parte importante nas emissões de GEE, tendo em vista sua logística (transporte de passageiros) e infraestrutura (alojamento). Dados publicados pela Organização Mundial do Turismo et al. (2008) calcularam as emissões de $\mathrm{CO}_{2}$ em três subsetores turísticos: transporte, alojamento e atividades turísticas de lazer. A organização considera que as emissões provenientes de fontes nacionais e internacionais geradas pelo turismo, nestes três subsetores da cadeia produtiva, representam em torno de $4,9 \%$ das emissões mundiais de GEE.

Em meio ao debate sobre causas e consequências da mudança climática, a ativi- 
dade turística tem uma produção científica que evidencia um conhecimento do turismo com respeito a adaptação e mitigação das mudanças climáticas em países desenvolvidos (Scott et al.; Rayamajhi, 2012; Grimm et al., 2013). Entretanto, o setor está diante de um fenômeno que não pode ser controlado e que, exige planificar estratégias de adaptação e mitigação que permitam desenvolver atividades turísticas em longo prazo com vistas ao enfrentamento da nova ordem climática.

Diante disso, este artigo analisa impactos, oportunidades e desafios para o desenvolvimento sustentável do turismo no Brasil, a partir dos cenários projetados pela mudança climática global. A metodologia tem abordagem interdisciplinar e sistêmica, de cunho descritivo/analítico, realizada a partir de pesquisa bibliométrica, documental e entrevistas junto aos especialistas na temática do turismo, desenvolvimento e mudanças climáticas. Como resultados tem-se a construção de cenários prospectivos que mostram possíveis impactos e consequências das mudanças climáticas ao sistema turístico internacional, constituindo-se em informações valiosas tanto para fins de mitigação, como de planejamento de ações de adaptação e minimização de impactos e vulnerabilidades.

\section{REFERENCIAL TEÓRICO}

\subsection{Mudanças climáticas e o turismo: desa- fios globais}

Em um cenário de mudanças climáticas é essencial que se reflita sobre o tema no que se refere ao contexto global, suas causas e consequências. Como impacto direto, a mudança do clima está relacionada não somente com a perda da biodiversidade e aumento de riscos naturais, mas também com impactos sociais na medida em que ameaça o crescimento econômico e a estabilidade política das nações. Para Santos (2000), a "mudança climática pode ser entendida como sendo todas as formas de inconstâncias climáticas, independentemente de sua natureza estatística ou causas físicas", podendo ser analisadas em diversas escalas temporais e em escalas espaciais (p. 66).

Com a Revolução Industrial, a partir do século XVIII, tem se intensificado a utilização de combustíveis fósseis, como o carvão mineral e derivados de petróleo. $\mathrm{O}$ uso crescente desses elementos, fez com que a composição da atmosfera alterasse, aumentando a quantidade de gases de longa vida, principalmente o $\mathrm{CO}_{2}$.

O Painel Intergovernamental sobre Mudanças Climáticas -IPCC (2014), em seu último relatório reafirmou que as mudanças climáticas estão ocorrendo e suas causas são derivadas das ações antropogênicas. O relatório, intitulado "Mudanças Climáticas 2014: Impactos, Adaptação e Vulnerabilidade", foi elaborado pelo Grupo de Trabalho II do IPCC e detalha os impactos das mudanças climáticas. $\mathrm{O}$ documento conclui que a resposta às mudanças climáticas envolve fazer escolhas sobre os riscos em um mundo em transformação.

As contradições entre o estilo de desenvolvimento adotado pelos países e a sustentação deste pela natureza são visíveis. A mudança climática afeta diretamente os elementos básicos da vida no Planeta, como o 
acesso a água, produção de alimentos, saúde e meio ambiente, causando aumento de pressão sobre os recursos naturais aliados a grande urbanização, industrialização e desenvolvimento econômico.

Neste cenário, uma das áreas afetadas pelas mudanças climáticas é o turismo. De acordo com o documento "Mudanças Climáticas e Turismo: responder aos desafios mundiais", elaborado pela Organização Mundial do Turismo (OMT), em parceria com o Programa das Nações Unidas para o Meio Ambiente (PNUMA) e a Organização Meteorológica Mundial (OMM), produzido a partir da 2a Conferência Internacional sobre Mudanças do Clima e Turismo (Davos, Suíça, 1 a 3 de outubro de 2007), as mudanças do clima afetarão os destinos turísticos, sua competitividade e sustentabilidade em quatro grandes áreas: Impactos climáticos diretos; Impactos indiretos das mudanças ambientais; Impactos das políticas de mobilidade e da redução do Turismo; e Impactos indiretos das mudanças sociais (Brasil, 2008).

A Conferência reuniu pessoas de vários setores para estudar a evolução do tema e reorientar o futuro. A Declaração de Davos (2007) reconheceu a mudança climática e sua forte relação com o turismo. Também admite a necessidade de uma estratégia a longo prazo para que o setor reduza as emissões de GEE e iniciativas concretas de governos, empresas, consumidores e redes de investigação e comunicação para fomentar a sensibilização e educação frente as mudanças climáticas (OMT, 2007).

Após a Conferência de Davos, os temas relacionados com a mudança climática e o turismo voltaram à tona nos debates na $\mathrm{Ci}$ meira Ministerial celebrada em Londres em 13 de novembro de 2007, Assembleia Geral da OMT em Cartagena das Índias (Colômbia) de 23 a 29 de novembro de 2009 e Conferência sobre Mudança Climática das Nações Unidas (COP 21), realizada em Paris em 2015. A COP 21 foi aprovado por 195 países com o objetivo de reduzir emissões de GEE no contexto do desenvolvimento sustentável. Os encontros levaram em conta que o turismo deve encontrar medidas de consenso face à mudança climática.

O clima encontra-se entre os fatores que motivam e determinam boa parte dos fluxos e tendências turísticas. Entretanto, a mudança climática tem afetado muitos destinos turístico, onde eventos extremos de seca, tempestade, grandes volumes de chuva, furacões entre outros tem tornado muitas regiões e comunidades globais vulneráveis a estes eventos. Mas, da mesma forma como é influenciado pelas mudanças do clima, o turismo tem contribuído para o aquecimento global.

De acordo com Peeters et al. (2017), os impactos ambientais do turismo que contribuem para as emissões de GEE podem ser observados a partir do consumo de energia, uso de combustíveis fósseis e o transporte de turistas. Tais impactos constituem-se o problema ambiental mais urgente relacionado ao turismo, impondo ao setor o desafio de encontrar mecanismos que permitam reduzir os impactos ambientais, fazendo com que os países diminuam os níveis de emissões de dióxido de carbono $\left(\mathrm{CO}_{2}\right)$, um dos elementos responsáveis pelo aquecimento global. 
Apesar dos novos desafios, até recentemente, tanto o setor turístico como a comunidade acadêmica, pouco têm pesquisado sobre os impactos das alterações climáticas na atividade turística e, inversamente, sobre o peso que o turismo e atividades com ele relacionadas, têm surtido nas mudanças ambientais globais (Scott et al., 2009).

De toda forma, segmentos turísticos ${ }^{4}$ expostos a eventos climáticos extremos poderão cada vez mais ser influenciados pela mudança climática, afetando sua infraestrutura e exigindo medidas de preparação para emergências, elevando os gastos de manutenção e interrompendo por vezes a atividade comercial (Scott et al., 2012; Fitchett et al., 2016). Isso significa, de acordo com a OMT (2007) que, mesmo sob condições atuais, a rentabilidade e viabilidade do destino turístico é parcialmente influenciada pelo clima.

Em relação ao aumento da temperatura global, esta poderá encurtar o período das estações de inverno, diminuindo as camadas de gelo e, além de diminuir o potencial turístico das estações de neve, poderia inclusive vir a inviabilizar a realização do turismo, gerando toda uma problemática econômica e social nas regiões mais afetadas. Contudo, há o outro lado da situação, pois, da mesma forma que a mudança climática pode inviabilizar a prática do turismo em regiões mais conhecidas, poderá destacar o potencial turístico de regiões pouco, ou até então não exploradas. De toda forma é importante perceber a relação de reciprocidade

\footnotetext{
${ }^{4}$ Principais segmentos turísticos no Brasil: turismo de
} sol e praia, ecoturismo, turismo social, cultural, de existente entre o turismo e a mudança climática, como a mudança no clima irá afetar a atividade turística, e como a poluição gerada pelo turismo contribuirá para o aquecimento global (Scott et al., 2009; Ficchett et al., 2015).

Diante disso, a estratégia está em promover iniciativas que conduzam a uma série de mudanças. Entre elas utilizar uma matriz energética mais limpa, legislações mais severas em relação à conservação dos ecossistemas naturais, educação ambiental, melhora nas práticas agrícolas, redução do consumo e do desperdício, política ambiental e turística adequada, entre outros, assegurando assim condições de sustentabilidade às gerações futuras.

\subsection{Consequências da mudança climática: cenários observados para o setor turís- tico}

Cenários de acordo com o IPCC são imagens do futuro, não são previsões nem predições. Permitem estabelecer e avaliar a vulnerabilidade socioeconômica e ambiental de referência anterior à mudança climática, determinar os impactos dessas mudanças e avaliar a vulnerabilidade depois da adaptação (IPCC, 2001).

Os principais cenários utilizados em pesquisas de mudanças climáticas são os de emissões, climáticos, ambientais e os de vulnerabilidades (Koumrouyan, 2010). No quadro 1, são identificadas de acordo com Stern (2006); OMT (2007); Moreno (2010); Grimm

estudos e intercâmbios, de pesca, de esportes, náutico, aventura, gastronômico, rural, saúde. 
et al.; IPCC (2013); e o Painel Brasileiro para as Mudanças Climáticas -PBMC (2014), tendências adotando como referência, projeções com mudanças climáticas globais a partir de dois cenários moderados de elevação da temperatura $(+2 \stackrel{\circ}{\circ}$ e $+3 \circ \mathrm{C})$, e incorporando os efeitos das mudanças em diferentes setores incluindo o turístico.

As causas e consequências da mudança climática sob a ótica do aquecimento caracterizam-se por ser de abrangência global (IPCC, 2007). No entanto, manifesta-se de maneira desigual nas mais diversas regiões do mundo (Stern, 2006; Welzer, 2010). Países pobres deverão enfrentar as maiores consequências mesmo não sendo estes responsáveis pela maior parte da emissão de GEE. A mudança climática poderá afetar os elementos básicos da vida como o acesso a água, produção de alimentos, saúde e meio ambiente causando aumento de pressão sobre os recursos naturais aliados a grande urbanização, industrialização e desenvolvimento econômico.

A mudança climática afeta a atividade turística tendo relação direta e principal com a escassez hídrica. Em relação aos destinos turísticos de praia, os impactos relacionados à mudança climática também deverão ser observados, onde a elevação do nível do mar, poderá prejudicar a parcela da população residente na zona costeira, devido à concentração de pessoas e os serviços disponibilizados nestas regiões (Kron, 2008).
Carmo e Silva (2009) avaliaram o conjunto de populações expostas ao risco de elevação do nível do mar e identificaram 24,3 milhões de habitantes residindo em áreas urbanas costeira, contingente este mais diretamente exposto ao risco. Em relação ao turismo, os autores identificam que os efeitos deverão ser sentidos no aumento dos eventos de inundação e no agravamento dos processos erosivos (perda de praia). Além disso, a infraestrutura urbana e turística localizada na zona costeira poderá ser danificada.

Refletindo sobre a magnitude potencial que as mudanças climáticas poderão representar no setor de turismo, Moreno (2010) aponta que o relatório AR4 do IPCC (2007), sobre impactos, adaptação e vulnerabilidade, esclarece que há considerável diversidade, onde o turismo é tratado regionalmente, revelando lacunas geográficas importantes na literatura e nas pesquisas. Ou seja, no relatório do IPCC (2014), o turismo recebe pouca ou quase nenhuma atenção. Considera-se que algumas discussões poderiam ser esperadas, relacionadas, por exemplo, com o efeito de ondas de calor sobre o turismo, e a competição por água entre o turismo e outros setores, mas isso não acontece. $O$ tratamento também é limitado nos capítulos da sustentabilidade e nas inter-relações entre adaptação e mitigação. 
Quadro 01 - Impactos globais projetados, a partir da elevação da temperatura

\begin{tabular}{|c|c|c|}
\hline SETORES & IMPACTOS A $2^{\circ} \mathrm{C}$ & IMPACTOS A $3^{\circ} \mathrm{C}$ \\
\hline $\begin{array}{l}\text { Agricultura } \\
\text { Alimentos }\end{array}$ & $\begin{array}{l}\text { Declínio da produção das colheitas em } \\
\text { regiões tropicais ( } 50 \% \text { dos cereais, } \\
25 \% \text { de milho e } 10 \% \text { de soja). Au- } \\
\text { mento das desigualdades e conflitos } \\
\text { pela escassez de alimentos e água. } \\
\text { Centro-Oeste e Nordeste brasileiro } \\
\text { sofrerão queda da produção agrícola. }\end{array}$ & $\begin{array}{l}600 \text { milhões de pessoas adicionais podem estar vi- } \\
\text { vendo em risco de fome. Aumento dos preços } \\
\text { mundiais dos alimentos. O nordeste brasileiro será } \\
\text { uma das regiões mais afetadas do mundo. É prová- } \\
\text { vel que a produção agrícola de altas latitudes au- } \\
\text { mente. }\end{array}$ \\
\hline Água & $\begin{array}{l}\text { Potencial decréscimo de } 20 \text { a } 30 \% \text { na } \\
\text { disponibilidade de água em algumas } \\
\text { regiões, por exemplo, o sul da África e } \\
\text { o Mediterrâneo. De } 600 \text { milhões a } 3 \\
\text { bilhões de pessoas ameaças pela es- } \\
\text { cassez de água. }\end{array}$ & $\begin{array}{l}1 \text { a } 4 \text { bilhões de pessoas sofrerão escassez de água. } \\
\text { Possíveis migrações ocasionadas pela seca provo- } \\
\text { cando instabilidade socioeconômica e política. A } \\
\text { Caatinga se tornará mais árida e a Amazônia sofrerá } \\
\text { períodos intensos de seca. }\end{array}$ \\
\hline $\begin{array}{l}\text { Saúde Hu- } \\
\text { mana }\end{array}$ & $\begin{array}{l}90 \text { a } 200 \text { milhões de pessoas correrão } \\
\text { risco de contrair malária ou outras do- } \\
\text { enças transmissíveis por insetos ou } \\
\text { água. Altas taxas de diarreia e subnu- } \\
\text { trição em países de baixa renda. }\end{array}$ & $\begin{array}{l}\text { Mais de } 300 \text { milhões de pessoas correrão o risco de } \\
\text { serem contaminadas por malária e } 5 \text { a } 6 \text { milhões } \\
\text { pela dengue. }\end{array}$ \\
\hline $\begin{array}{l}\text { Ecossistema } \\
\text { Biodiver- } \\
\text { sidade }\end{array}$ & $\begin{array}{l}15 \text { a } 40 \% \text { de espécies enfrentando pe- } \\
\text { rigo de extinção. Perda de } 95 \% \text { da } \\
\text { maioria dos corais, impactos sobre a } \\
\text { pesca comercial e de subsistência. } \\
\text { Risco de alteração permanente dos } \\
\text { sumidouros de carbono para fontes } \\
\text { de carbono (Amazônia). Grande por- } \\
\text { ção da Tundra e metade das florestas } \\
\text { boreais pode desaparecer. }\end{array}$ & $\begin{array}{l}\text { Começo do colapso da floresta Amazônica: perdas } \\
\text { de mais de } 10 \% \text { das espécies de peixe; de } 22 \% \text { de } \\
\text { zonas úmidas nas costas. } 50 \% \text { espécies em perigo } \\
\text { de extinção, incluindo } 25 \text { a } 60 \% \text { de mamíferos, } 30 \\
\text { a } 40 \% \text { pássaros e } 15 \text { a } 70 \% \text { de borboletas no sul da } \\
\text { África. Risco de } 88 \% \text { de transformação de florestas } \\
\text { para sistema não florestais. Possível perda e ex- } \\
\text { tinção de espécies dependentes de gelo. }\end{array}$ \\
\hline Geleiras & $\begin{array}{l}60 \% \text { de perda de gelo no Ártico du- } \\
\text { rante o verão. Groelândia derreti- } \\
\text { mento completo e irreversível. } \\
\text { Diminuição de } 25 \% \text { ou mais do gelo } \\
\text { oceânico. }\end{array}$ & $\begin{array}{l}\text { Perda total do gelo oceânico durante o verão no Ár- } \\
\text { tico. Perda completa da camada de gelo da Groe- } \\
\text { lândia e das geleiras da Antártida com aquecimento } \\
\text { de } 3^{\circ} \mathrm{C} \text { por vários séculos. }\end{array}$ \\
\hline $\begin{array}{l}\text { Mares e } \\
\text { oceanos }\end{array}$ & $\begin{array}{l}\text { Aumento do nível do mar e inunda- } \\
\text { ções costeiras poderá colocar em } \\
\text { risco } 25 \text { a } 50 \text { milhões de pessoas. Al- } \\
\text { tos custos de recuperação. }\end{array}$ & $\begin{array}{l}\text { Aumento do nível do mar, inundações costeiras e } \\
\text { stress hídrico colocarão em risco } 180 \text { milhões de } \\
\text { pessoas. Centenas de milhares terão que migrar. }\end{array}$ \\
\hline $\begin{array}{l}\text { Eventos ex- } \\
\text { tremos do } \\
\text { clima }\end{array}$ & $\begin{array}{l}\text { Aumento na frequência e intensidade } \\
\text { de inundações, secas, tempestades, } \\
\text { ondas de calor, ciclones tropicais e ou- } \\
\text { tros eventos extremos. Sul e sudeste } \\
\text { do Brasil vulneráveis a estes eventos. }\end{array}$ & $\begin{array}{l}\text { Aumento na frequência e intensidade de incêndios, } \\
\text { secas, tempestades, ondas de calor. Perdas socioe- } \\
\text { conômicas principalmente para países e regiões } \\
\text { mais pobres do mundo. }\end{array}$ \\
\hline Turismo & $\begin{array}{l}\text { Desconforto pela alta temperatura, } \\
\text { provocando diminuição da demanda } \\
\text { em muitos destinos turísticos de sol e } \\
\text { praia. Novos destinos podem surgir } \\
\text { principalmente em Unidades de Con- } \\
\text { servação, implicando superlotação } \\
\text { nessas áreas e impactos ecológicos. }\end{array}$ & $\begin{array}{l}\text { Reduções máximas nas estações (primavera e ve- } \\
\text { rão) na umidade relativa, incremento da insolação } \\
\text { provocando perdas para certas modalidades de tu- } \\
\text { rismo. Redução de áreas turísticas com comprome- } \\
\text { timento do setor de turismo de inverno (neve). Di- } \\
\text { minuição da demanda implicará perda econômica } \\
\text { para destinos de montanha (derretimento da } \\
\text { neve); costeiro (subida do mar, branqueamento e } \\
\text { mortalidade de recifes de coral). }\end{array}$ \\
\hline
\end{tabular}

Fonte: Stern (2006); IPCC (2013); PBMC (2014); OMT (2007); Moreno (2010); Grimm et al., (2013). 
Por adaptação entende-se as possíveis respostas dos ecossistemas aos impactos atuais e potenciais da mudança do clima, buscando minimizar possíveis anomalias e explorar oportunidades potenciais. A mitigação pode ser entendida como ações que reduzam o uso de recursos naturais e implementação de medidas que diminuam as emissões de GEE e que beneficiem a recuperação, regeneração e criação de sumidouros (Grimm, 2016).

Diante do exposto e observada a complexidade dos impactos das mudanças climáticas para todos os setores econômicos e, considerando-se as interações entre o sistema social e o ecológico, são necessários estudos e pesquisas interdisciplinares que levem em conta os fatores da vulnerabilidade em múltiplas escalas. Considerando que as respostas aos impactos das mudanças climáticas consistirão primordialmente de respostas individuais na escala local, é necessário que essa perspectiva multiescalar seja aplicável à análise da capacidade adaptativa no nível das comunidades (Dolan \& Walker, 2004). Neste contexto, o turismo deve ser inserido nas pesquisas, pois constitui-se alternativa de desenvolvimento para nações que dela dependem economicamente.

\section{METODOLOGIA}

Os dados dessa pesquisa foram coletados a partir da análise bibliométrica e documental que dispunham dados relativos à atividade turística e sua interação com as mudanças climáticas. Nesse ponto, algumas lacunas impediram a fluência da pesquisa uma vez que a revisão do tema neste campo mostra-se ainda escassa. Todavia, para o constructo deste campo temático, sobretudo para analisar as possibilidades e os desafios que as mudanças climáticas deverão impor ao setor de turismo, a coleta de dados contou com a colaboração de especialistas e pesquisadores oriundos de diferentes áreas do conhecimento compondo um quadro interdisciplinar de experts.

Assim, nos meses de janeiro a maio de 2015, foram selecionados e contribuíram para a pesquisa participantes de universidades nacionais: Estadual de São Paulo (USP), Federal do Pará (UFPA), do Ceará (UFC), Estadual da Bahia (UNEB) e; universidades estrangeiras: de Coimbra (Portugal), de BarceIona (Espanha), Austral do Chile e King's College London (Inglaterra). Contou também com colaboradores de instituições como o Painel Intergovernamental para as Mudanças Climáticas (IPCC), Painel Brasileiro para as Mudanças Climáticas (PBMC) e do Instituto Nacional de Pesquisas Espaciais (INPE). No total contribuíram quinze especialistas de diferentes áreas disciplinares: meteorologia, física, sociologia, ciências econômicas, geografia, turismo, administração, ciências sociais, biologia e engenharia ambiental.

\subsection{Instrumental da pesquisa}

$O$ instrumento de pesquisa constituiu-se de entrevista estruturada, cuja abordagem relacionou o turismo com as mudanças climáticas e desenvolvimento sustentável. O convite e o envio dos questionários aos especialistas foi via telefone ou e-mail, informando os objetivos da pesquisa. Com o retorno dos questionários foi realizada a aná- 
lise das informações para verificar a validade dos dados. Nesse ponto, o retorno dos questionários foi satisfatório, não sendo necessário solicitar esclarecimentos ou novas informações.

Por se tratar de pesquisa bastante específica, elaborou-se um questionário que foi enviado aos colaboradores, com vistas a responder ao objetivo da pesquisa: analisar os impactos, oportunidades e desafios para o desenvolvimento sustentável do turismo no Brasil, a partir dos cenários projetados pela mudança climática global. Questionou-se: i) diante das mudanças climáticas, quais são os impactos que podem ser esperados ao setor de turismo no Brasil e no mundo? ii) é possível articular ações de mitigação e adaptação do setor frente aos desafios da mudança climática? iii) a partir dos cenários projetados pelas mudanças climáticas é possível apontar oportunidades e desafios para o desenvolvimento do turismo? iv) em que medida a criação ou manutenção de Unidades de Conservação tornam-se elemento de regulação e mitigação das emissões de GEE? v) é possível promover um desenvolvimento de baixa emissão de GEE, tendo o turismo como atividade que contribua para essa redução?

A partir dos dados coletados foi possível sistematizar as contribuições dos especialistas de cada área disciplinar e, a partir destas informações juntamente com os dados obtidos na pesquisa bibliométrica relativizálas e formatar o constructo teórico denominado, resultados.

\subsection{Análise dos dados}

Para análise do conteúdo, os resulta- dos são tratados de maneira a serem significativos e válidos. Nesse sentido, as categorias de análise: mudanças climáticas, turismo e desenvolvimento, adaptação, mitigação e baixo carbono servem para transformar as informações obtidas junto aos especialistas em dados que sejam interpretáveis e tenham significados conforme o objetivo da pesquisa.

O cruzamento dos dados foi organizado em torno da categorização que consistiu em descobrir os núcleos de sentido que compõe o aporte de cada especialista consultado. De acordo com a proposta de Bardin (2011) levou-se em consideração a regra de exclusividade, em que uma frase presente em uma categoria não pode estar em outra, bem como a regra de homogeneidade, princípio que define uma categoria como sendo necessário haver só uma dimensão na análise. Com sucessivas leituras dos dados, foi possível chegar aos "resultados" dando a entender as principais implicações, desafios e possibilidades a partir das mudanças climáticas para o desenvolvimento sustentável do turismo.

\section{RESULTADOS E DISCUSSÕES}

\subsection{Mudança climática: impactos e desafios para o desenvolvimento do turismo na- cional}

Reconhecidas as limitações em torno do conhecimento que trata a relação turismo e mudanças climáticas (Simpson et. al., 2008; SCOTT et al., 2009; Moreno, 2010; Grimm et al., 2013), os resultados aqui apresentados têm por base a pesquisa bibliométrica, documental e do encontro de olhares e conheci- 
mentos identificados entre os especialistas consultados.

Assim, ao analisar a magnitude potencial que as mudanças climáticas poderão representar para o turismo global, pesquisas apontam impactos significativos. Contudo, a falta de observações de longo prazo é um fator limitante para diagnosticar e quantificar o papel dos diferentes agentes do clima no sistema turístico (demanda, oferta, espaço geográfico turístico e agentes).

Da mesma forma, as pesquisas realizadas correspondem a regiões específicas (ilhas e destinos turísticos de neve), não trazendo em seu bojo informações relevantes para a atividade turística no Brasil. Isso poderia ser justificado pelo fato de que apesar da crescente atenção na relação, turismo e mudanças climáticas a partir da década de 1990, o campo ainda é relativamente inexplorado, devido, principalmente ao pouco investimento governamental na investigação das dimensões ambiental e social do turismo. Outro fator limitante está no fato de que os estudos interdisciplinares ligados ao tema, mesmo entre aqueles que desempenham papel relevante na área das políticas públicas e instituições governamentais, ainda parece ser pouco expressivo.

Notadamente uma das características básicas do turismo brasileiro é a diversidade e abundância de seus recursos, cuja exploração deu lugar ao desenvolvimento turístico diferenciado no tempo e espaço, e a criação de inúmeros produtos, onde se identificam regiões com intensidades turísticas desiguais e qualitativamente distintas. Estas características que identificam o produto turístico es- tão diretamente relacionadas ao entorno geográfico, definido tanto pela natureza dos componentes do meio, como por sua função territorial. Entre as condições geográficas que perfilam os traços dos referidos entornos destaca-se o clima, que confere peculiaridade e diversidade a cada região, resultando na identificação de cenários para áreas turísticas de litoral, montanha, zonas urbanas e rurais.

Com base nestas áreas (litoral, montanha, zonas urbanas e rurais) buscou-se identificar os cenários das mudanças climáticas e suas consequências para o turismo nacional. Contudo, as quatro áreas apresentam uma escala de análise com certo grau de abstração que oculta heterogeneidades, problemas específicos, contrastes ambientais e diversidade climática. Portanto, estas zonas deverão ser afetadas de forma desigual, pois, além das características específicas, dispõe também de diversidade na oferta de recursos, produtos e destinos onde cada qual mantém diferente grau de relação com o clima.

De acordo com o caráter e a escala de análise com que se operou neste trabalho os informes extraídos de estudos científicos e do aporte dos especialistas, detectou-se que as áreas mais vulneráveis estão relacionadas ao litoral e montanha. Esta vulnerabilidade aos impactos da mudança climática não é particular do Brasil, este cenário de acordo com Mello et al. (2009) pode ser verificado em outros destinos turísticos mundiais.

Ancorado na contribuição dos especialistas observou-se impactos, consequências e desafios que o setor de turismo poderá en- 
frentar frente às mudanças climáticas (Quadro 2). Destaca-se que as consequências poderão provocar efeitos diferenciados para cada um dos componentes do sistema turístico: espaço geográfico turístico, demanda, oferta e agentes. Em relação ao sistema de turismo os impactos podem ser esperados a partir do aumento da temperatura global, redução nas precipitações e aumento na sua variabilidade interanual, aumento dos eventos climáticos extremos e elevação no nível do mar.

Quadro 2 - Impactos, consequências e desafios ao setor de turismo frente as mudanças climáticas

\begin{tabular}{|c|c|c|c|}
\hline FATORES & IMPACTOS & CONSEQUÊNCIAS & DESAFIOS \\
\hline $\begin{array}{c}\text { Aumento de } \\
\text { temperatura } \\
\text { (oferta e de- } \\
\text { manda) }\end{array}$ & $\begin{array}{l}\text { - Redução do perí- } \\
\text { odo adequado de } \\
\text { exposição solar } \\
\text { - Stress térmico } \\
\text { - Aumento na inci- } \\
\text { dência de câncer } \\
\text { de pele }\end{array}$ & $\begin{array}{l}\text { - Redirecionamento da de- } \\
\text { manda para outros destinos } \\
\text { potenciais, como as unidades } \\
\text { de conservação } \\
\text { - Adaptação do período da via- } \\
\text { gem } \\
\text {-Fragmentação do período de } \\
\text { férias com diminuição da esta- } \\
\text { dia } \\
\text { - Má qualidade da experiência }\end{array}$ & $\begin{array}{l}\text { - Promover uma atividade de } \\
\text { baixo carbono } \\
\text { - Ofertar destinos de natureza } \\
\text { em todos os períodos do ano } \\
\text { - Promover ações e campa- } \\
\text { nhas informando sobre os cui- } \\
\text { dados em relação à exposição } \\
\text { ao sol }\end{array}$ \\
\hline $\begin{array}{l}\text { Eventos extre- } \\
\text { mos } \\
\text { (espaço geo- } \\
\text { gráfico turís- } \\
\text { tico, de- } \\
\text { manda, oferta } \\
\text { e agentes) }\end{array}$ & $\begin{array}{c}\text {-Destruição da in- } \\
\text { fraestrutura turís- } \\
\text { tica } \\
\text { - Bloqueio de vias } \\
\text { de acesso } \\
\text { - Interrupção nos } \\
\text { meios de comuni- } \\
\text { cação } \\
\text {-Mudanças do ciclo } \\
\text { hidrológico }\end{array}$ & $\begin{array}{l}\text { - Especulação imobiliária; } \\
\text { - Contaminações e propagação } \\
\text { de doenças } \\
\text { - Falta de água potável } \\
\text {-Alto custo de recuperação } \\
\text {-Baixa capacidade de atendi- } \\
\text { mento emergencial (resgate, } \\
\text { evacuação, serviços médicos) } \\
\text { - Indisponibilidade de acomo- } \\
\text { dações de emergência, aconse- } \\
\text { Ihamento e atendimento às ví- } \\
\text { timas } \\
\text { - Aumento no preço das via- } \\
\text { gens } \\
\text {-Insegurança } \\
\text { - Má qualidade da experiência } \\
\text { - Desconfiança do consumidor }\end{array}$ & $\begin{array}{c}\text { - Fomentar novos destinos tu- } \\
\text { rísticos, mais sustentáveis } \\
\text { - Promover ações e campa- } \\
\text { nhas informando sobre a pro- } \\
\text { teção e uso racional dos recur- } \\
\text { sos } \\
\text { - Novos investimentos, tecno- } \\
\text { logias e estratégias de comer- } \\
\text { cialização } \\
\text { - Criar planos e ações e desen- } \\
\text { volver estratégias para lidar } \\
\text { com as consequências dos } \\
\text { eventos extremos } \\
\text { - Implantar medidas de alerta } \\
\text { que antecipem ocorrências de } \\
\text { eventos extremos e medidas } \\
\text { para amenizar o problema e } \\
\text { proteger a população local e o } \\
\text { turista }\end{array}$ \\
\hline $\begin{array}{l}\text { Elevação do ní- } \\
\text { vel do mar } \\
\text { (espaço geo- } \\
\text { gráfico turís- } \\
\text { tico, oferta e } \\
\text { agentes) }\end{array}$ & $\begin{array}{l}\text { - Degradação de } \\
\text { praias } \\
\text { - Branqueamento } \\
\text { de corais } \\
\text { - Erosão costeira } \\
\text { - Destruição de } \\
\text { manguezais } \\
\text { - Destruição da in- } \\
\text { fraestrutura da orla }\end{array}$ & $\begin{array}{c}\text { - Diminuição do espaço junto à } \\
\text { areia para o lazer } \\
\text { - Impactos na reserva de água } \\
\text { doce } \\
\text { - Alto custo da restauração da } \\
\text { orla }\end{array}$ & $\begin{array}{c}\text { - Promover ações e iniciativas } \\
\text { de mitigação e adaptação } \\
\text { - Planejar e ordenar o uso e } \\
\text { ocupação territorial à beira } \\
\text { mar } \\
\text { - Implantação de obras de en- } \\
\text { genharia costeira }\end{array}$ \\
\hline
\end{tabular}

Fonte: Grimm (2016), baseado na contribuição dos especialistas. 
Entre os possíveis impactos da mudança do clima sobre o turismo brasileiro, Coriolano (2015) expõe:

\begin{abstract}
(...) um exemplo emblemático da atividade na zona costeira do Ceará, onde as alterações na temperatura do planeta de acordo com a especialista podem gerar aumento do nível do mar, e consequentemente aumentar eventos de inundação e agravar processos erosivos de praia. Além disso, a infraestrutura urbana e turística localizada na zona costeira pode ser danificada. A alternativa para reduzir os danos desses impactos, pode ser a implantação de obras de engenharia costeira, mas, que em contrapartida podem afetar a balneabilidade e a beleza cênica do litoral (Especialista consultada, 2015).
\end{abstract}

Outros destinos turísticos no Brasil poderão ter algumas de suas praias afetadas, principalmente entre os meses de julho a setembro, quando os ventos são mais fortes e as marés estão mais altas. As causas do avanço do mar estão relacionadas aos efeitos locais (erosão, atividade humana, engenharia e ocupações) e o efeito global, que é o aquecimento do planeta. Também existem variações temporais do nível do mar que podem influir nos números de longos períodos. Como consequência, a água invade e destrói a infraestrutura construída na orla marítima (Marengo, 2007; PBMC, 2014).

No estado do Paraná, o trecho da orla de Praia Grande em Matinhos é exemplo de áreas litorâneas degradadas pela erosão acentuada, ocupações irregulares invadindo a linha costeira, desembocadura de rios com águas provavelmente contaminadas por ligações de esgoto clandestinas, ajardinamento da orla sem critérios com introdução de es- pécies exóticas inseridas na área de restinga, execução de obras de infraestrutura de lazer e acesso à praia sem critérios e com supressão de dunas e restinga e construções na área de domínio público. Tais condições não são decorrentes exclusivamente das mudanças climáticas, mas esta pode agravar as situações de vulnerabilidade do litoral decorrente de chuvas intensas, elevação do nível do mar, tempestades e outros fenômenos que podem impactar, sobremaneira, comunidades costeiras e suas atividades produtivas.

A mudança climática está contribuindo provocando elevações do nível do mar e provocando tempestades que tornam vulneráveis as faixas de praia, onde a escassez progressiva da areia pode fazer com que algumas praias do litoral brasileiro desapareçam principalmente em áreas urbanizadas, regiões que correm maior risco, pois geralmente a perda de areia não é reposta naturalmente e a orla sofre grande erosão. Ademais, as ressacas com ondas acima de três metros de altura e marés meteorológicas elevadas potencializarão esses impactos em toda a zona costeira. Há ainda um efeito ocasional, que é a mudança nos padrões de circulação atmosférica, com alteração no regime das ondas (Rosman, 2007).

Por outro lado, as temperaturas mais amenas no sul do país podem de alguma forma favorecer o turismo de praia fora do período de verão (AMBRIZZI, 2015). Os cenários simulados a partir da mudança climática no turismo litorâneo apontam que poderá haver deslocamento da temporada turística devido à intensificação de um período estival mais quente e seco. Por outro lado, poderá 
favorecer a ampliação e desestacionalização da mesma. Poderá ocorrer uma fragmentação do período de férias laborais, para meIhor aproveitar as condições atípicas do clima (por excesso de calor fora de temporada) e melhores condições econômicas (promoção de viagens com preços mais acessíveis).

Verões cada vez mais quentes poderão promover economias locais de forma indireta com a venda de produtos destinados a proteção contra os raios ultravioletas (protetores solares, chapéus, óculos etc.), e produtos que ajudem a amenizar o calor (bebidas, alimentos apropriados, sorvetes, ar condicionado, ventiladores etc.) que passa a ser necessidade básica do morador local e dos turistas (Marengo, 2015).

As projeções do clima, com base nos biomas brasileiros, mostram que particularmente na região Norte e parte do Nordeste deverá haver diminuição de chuvas, ocasionando falta de água, enquanto que no Sul haverá um aumento significativo na pluviosidade que poderá produzir eventos extremos de enchentes, alagamentos e inundações. Para a região Sudeste os extremos de chuva e seca são observados e ocasionam falta de água e inundações, com transtornos constantes à população.

Cenários demonstram que poderá agravar-se ainda mais a disponibilidade de água potável na zona litorânea, situação atualmente verificada em alguns balneários, onde a concentração sazonal da demanda turística exige alternativas de abastecimento. Neste contexto, sugere-se, a exemplo de outros destinos turísticos globais, a dessalinização da água do mar (Cabo Verde - África), aproveitamento dos recursos subterrâneos quando estes existirem e o aproveitamento de água da chuva (Palma de Mallorca - Espanha). A solução dessa questão é fator chave para a manutenção da atividade turística litorânea, em especial, no cenário de mudanças climáticas.

Nessa direção é observável a imposição de desafios à atividade turística em relação aos possíveis impactos que o clima possa representar ao setor. Consideram-se desafios a necessidade de minimizar os impactos nas dimensões: econômica, por meio de novos investimentos, tecnologias e estratégias de comercialização; ambiental com a proteção e uso racional dos recursos; social, promovendo a diminuição da pobreza, a diminuição da vulnerabilidade turística assegurando segurança física da comunidade receptora e do turista, caso acontece um evento climático extremo; política, promovendo ações e iniciativas de mitigação e adaptação e; espacial com adequado planejamento e ordenamento territorial.

Os impactos da mudança climática também poderão afetar a demanda turística de forma direta, interferindo na escolha do destino e no período temporal da viagem, ou de forma indireta afetando a qualidade da experiência, percepção adversa após algum evento extremo e na insegurança em relação ao destino.

Os eventos extremos aumentam as preocupações de turistas com segurança e proteção, colocando pressão crescente sobre planejadores e gestores envolvidos com o turismo, impelindo-os a analisar o impacto das catástrofes sobre o setor e a desenvolver estratégias para lidar com as consequências adversas (Maditinos \& Vassiliadis, 2008; Corio- 
lano, 2015 - Especialista consultada).

Neste contexto, observa-se que o sistema turístico está em constante adaptação, respondendo as mudanças ambientais, econômicas, políticas, demográficas, tecnologias e as novas demandas, atuando de forma específica de acordo com o território onde se insere o destino turístico. Portanto, Campos Filho (2015) destaca que:

(...) é importante realizar uma análise dos impactos adotando uma escala temporal e espacial e atendendo às características do local a ser estudado. Considerando um cenário macro, a mudança climática tem impactado negativamente todos os ambientes rurais e urbanos incluindo destinos turísticos vulneráveis (atuais e potenciais) independentes de bioma e de outras características geográficas (Especialista consultado, 2015).

Diante disso, regiões que receberem menor precipitação deverão tomar medidas no sentido de informar e educar o turista para o uso racional da água, promovendo tomada de consciência na redução do desperdício. Quanto aos empreendimentos implantar junto às atividades turísticas medidas simples, eficazes e ambientalmente corretas do uso da água e da energia. Atividades de lazer ou destinos turísticos que dependem da água (parques aquáticos, termas, etc.) devem atentar para a necessidade de diversificar suas atividades. Da mesma forma, destinos turísticos vulneráveis aos impactos de frequentes e intensas chuvas e seus efeitos adversos (deslizamentos, tempestades, inundações etc.) poderão ter rodovias e aeroportos afetados ocasionando atrasos ou interrompendo o deslocamento dos turistas. Estes destinos devem estar atentos e buscar medi- das de alertar que antecipem ocorrências de ventos, chuvas, raios, tempestades no sentido de tomar medidas para amenizar o problema e proteger a população local e o turista.

De toda forma ao sugerir que o setor do turismo faça frente aos novos desafios impostos pela mudança climática é aconselhável que se considere a relação local-global, intrínseca ao fenômeno das alterações climáticas, e as possíveis articulações e ações de movimentos locais com as propostas internacionais a respeito do tema. Contudo, Marengo (2015) adverte que apesar da articulação global/local ser possível é recomendável haver sinergia com ações regionais e globais, pois não adianta reduzir as emissões localmente se o "mundo continua liberando gases de efeito estufa" (Especialista consultado, 2015).

Para Ambrizzi (2015), o país como um todo deve demonstrar ao mundo que estamos fazendo nossa parte na redução de emissões de GEE e ter um desenvolvimento econômico sustentável. Talvez, assim, se possa influenciar mais decisivamente outras nações e com isso conseguir propor projetos e temas a todos os países para evoluir rumo a um consenso, inclusive daqueles que não assinaram o acordo global de redução, confirmado no Protocolo de Kyoto (Especialista consultado, 2015).

Para que as ações direcionadas ao enfrentamento dos desafios impostos pela mudança do clima alcance seus propósitos e revertam em benefícios às comunidades receptoras, turistas e às empresas de turismo serão necessárias parcerias entre os diversos segmentos no sentido de legitimar as ações e 
unir esforços em prol dos objetivos comuns. Reconhecendo esta necessidade Redclift (2015) aposta na ação coletiva e legitima da sociedade civil: "There needs to be specified links between individual and collective action and the need for strong community involvement. The key is the strength and legitimacy of civil society and its institutions" (Especialista consultado, 2015).

A mudança climática impõe desafios ao setor turístico, contudo, é possível identificar oportunidades para o desenvolvimento sustentável da atividade observando os cenários projetados pelas mudanças climáticas, principalmente em destinos mais vulneráveis aos eventos meteorológicos extremos, que podem afetar a vida das comunidades, seus bens e modos de vida, assim como a infraestrutura turística e os próprios turistas.

Nesse caso, Oliveira (2015) afirma que o desafio que se coloca ao buscar oportunidades, “(...) inclui todas as atividades econômicas e não apenas o turismo. É preciso administrar as mudanças que a ordem ecológica passará a nos impor mediante o agravamento da crise ambiental" (Especialista Consultado, 2015). Para Ambrizzi (2015) será possível “(...) gerar oportunidades por meio do conhecimento de como o clima irá

5 O Protocolo de Kyoto constitui um tratado complementar a Convenção-Quadro das Nações Unidas sobre Mudança do Clima. Criado em 1997, definiu metas de redução de emissões para os países desenvolvidos, responsáveis históricos pela mudança atual do clima (MMA).

6 O mercado de carbono instituído a partir do Protocolo de Kyoto tem por finalidade a comercialização de carbono. A partir da criação de Mecanismos de Desenvolvimento Limpo (MDL) é gerado excedente de carbono que por sua vez pode ser comercializado via o se desenvolver no futuro. Regiões mais quentes e secas, mais frias e úmidas poderão ser adaptadas para desenvolver ambientes propícios ao turismo da região" (Especialistas consultados, 2015).

Oportunidades surgem das mudanças. O setor de turismo deverá aproveitar o momento para criar condições e desenvolver uma economia de baixo carbono.

\subsection{Oportunidade para desenvolver uma ati- vidade turística de baixo carbono}

Em 16 de fevereiro de 2005, entra em vigor o Protocolo de Kyoto ${ }^{5}$, o documento "A economia das Mudanças Climáticas", conhecido também como Relatório Stern (Stern Review on the Economics of Climate Change) dá ênfase a oportunidade de negócios com o aquecimento global e a produção de agro combustível. A partir desse relatório, o termo economia de baixo carbono ${ }^{6}$ passa a fazer parte dos discursos governamentais. Todavia, a crise ambiental atual, deixa claro que não é possível conciliar crescimento com as alterações climáticas; ainda que o conceituado relatório Stern (2006) julgue que "não é incompatível a luta contra a mudança climática com a promoção do crescimento" (p.39),

mercado de carbono. Os MDL podem ser tanto de retenção de carbono como de minimização de emissão. O mercado de carbono busca negociar a redução das emissões de dióxido de carbono, teoricamente auxiliando na mitigação das mudanças climáticas. Para compor tal sistema, é preciso a elaboração de uma série de metodologias, regulamentações e estruturas de monitoramento e comercialização dos 'créditos' de redução das emissões. 
sua afirmação não aponta caminhos que conduzam a realização dessa utopia necessária.

Em relação à economia de baixo carbono é oportuno destacar que utilizar tecnologias e processos menos agressivos ao meio ambiente são essenciais, contudo, nem sempre essa é uma solução viável em curto prazo. De acordo com Frangilli (2007), a obtenção dos chamados "créditos de carbono" é um caminho novo, mas que merece ser bem avaliado por empresas e governos.

O Protocolo de Kyoto representa um esforço mundial para mitigar a mudança do clima, cujo texto previa que os países desenvolvidos, signatários do acordo, deveriam reduzir suas emissões em média $5 \%$ entre 2008 e 2012, com base em suas emissões de 1990. Estabeleceu ainda um mecanismo que permitiu projetos de redução de emissões em países em desenvolvimento, que não possuíam metas de redução de emissões no âmbito do protocolo, o Mecanismo de Desenvolvimento Limpo (MDL). O MDL é também o meio pelo qual os países que possuem compromissos quantificados de limitação ou redução de suas emissões de GEE possam atender parte desses compromissos por meio da obtenção de créditos de carbono. Ou seja, os países desenvolvidos poderão cumprir parte de suas metas de redução e limitação de emissões de GEE, por meio da aquisição de créditos de carbono gerados em projetos localizados nos países em desenvolvimento. Com isso, países como o Brasil, ampliam suas chances de desenvolvimento sustentável. Os projetos de MDL devem contemplar escopos como: substituição de combustíveis fósseis, eficiência energética, queima ou utilização do metano, entre outros. Para a remoção de carbono, foram aprovadas metodologias para florestamento e reflorestamento, onde ações voluntárias têm sido realizadas no âmbito da neutralização ou compensação das emissões. Contudo, deve haver cautela ao utilizar esse tipo de medida, uma vez que existem muitas dúvidas acerca de sua real eficácia (Frangialli, 2007, p. 32).

Viola (2010) avaliando as vantagens e desvantagens do Brasil na transição para uma economia de baixo carbono, destaca a importância de refletir sobre o potencial dos diversos setores da economia, pois muitos demonstram potenciais e interesse de suas lideranças na transição para uma economia de baixo carbono, entre elas o autor destaca o ecoturismo.

No setor de turismo a economia de baixo carbono pode ser traduzida como a prestação de serviços de hospedagem, transporte, alimentação e recreação que satisfaçam às necessidades da demanda, que busque melhor qualidade de vida da comunidade local e promova a redução progressiva dos impactos ambientais de tais serviços ao longo do ciclo de vida do produto. Ou seja, uma economia de baixo carbono para o setor deve valorizar produtos turísticos com menor impacto ecológico, que satisfaçam a crescente exigência ambiental da demanda, conservando a cultura das comunidades de acoIhimento (Grimm, 2016).

As iniciativas por um turismo de baixo carbono devem envolver todo o sistema turístico (demanda, população local, iniciativa privada, poder público e ONG), promovendo medidas de enfrentamento das mudanças climáticas em curto e médio prazo. Entre os objetivos principais que po- 
dem ser desenvolvidos rumo a uma economia de baixo carbono no setor Grimm (2016, p.66) destaca:

$\checkmark \quad$ Criar uma plataforma para que empresas turísticas possam calcular suas emissões de GEE e apresentar seus compromissos de redução;

$\checkmark$ Reunir estes compromissos de redução e divulgar os avanços e impactos alcançados aos diferentes grupos de interesse;

$\checkmark$ Promover campanhas de capacitação e informação sobre a economia de baixo carbono no setor de turismo;

$\checkmark$ Promover parcerias entre as empresas de turismo visando a redução de emissões de GEE;

$\checkmark$ Promover a realização de eventos científicos em temas prioritários sobre mudança climática e o turismo.

À luz desses princípios, o setor de turismo a partir da eficiência ecológica (ou ecoeficiência) apresenta-se como uma perspectiva que pode fornecer iniciativas consideradas mais sustentáveis.

Ecoeficiência é um termo cunhado pelo Conselho Empresarial Mundial para o Desenvolvimento Sustentável, criado em 1995, com base no ciclo de vida do produto, cuja abordagem de análise busca reduzir a utilização de recursos e minimizar os impactos ambientais. Ela tem sido utilizada, principalmente, no contexto da economia industrial para reduzir custos e criar oportunida- des de mercado com o efeito de diminuir o impacto sobre o meio ambiente (Cramer, 2000).

No turismo a ecoeficiência pode ajudar a tomada de decisões na negociação em emissão de carbono, contudo, Gossling et al. (2005) advertem que algumas questões devem ser observadas na aplicação do conceito de ecoeficiência. Entre elas, a necessidade de coletar dados detalhados sobre transporte, alojamento e atividades de lazer, bem como receitas geradas para os diferentes mercados. Isso pode muitas vezes revelar-se difícil, mas, apesar disso a ecoeficiência pode se tornar instrumento mais amplamente utilizado para o turismo sustentável (Gossling et al., 2005).

Coloca-se, assim, a necessidade dos destinos turísticos mais vulneráveis a eventos extremos (falta de água, ondas de calor, furacões, inundações, deslizamentos, elevação do nível do mar, etc.) buscarem adaptarse aos novos cenários ambientais e climáticos. Dessa adaptação podem emergir novas formas de fazer turismo como é o turismo comunitário, que busca se desenvolver como alternativa ao turismo de massa, ao privilegiar uma atividade de menor impacto ambiental.

Países em desenvolvimento, conforme sugerem os cenários apontados pelos especialistas consultados, são os mais vulneráveis aos impactos das mudanças climáticas e os menos capacitados para seu enfrentamento. Assim, tornam-se imprescindíveis os esforços para ampliar as pesquisas e a produção do conhecimento que possa informar aos tomadores de decisão, os direcionamentos necessários para o planejamento estratégico 
e a criação de políticas públicas que incluam o setor de turismo nas abordagens sobre as mudanças climáticas.

\section{CONSIDERAÇÕES}

Em geral, os resultados descrevem o comportamento médio do clima presente e, embora envolto em incertezas, as projeções das mudanças climáticas ao longo do século XXI constituem-se em informações valiosas tanto para fins de mitigação, como planejamento de ações de adaptação e minimização de impactos e vulnerabilidades. Levando em conta as projeções diferenciadas que implicam em potenciais impactos socioeconômicos e ambientais é recomendável o planejamento e tomada de decisão agora e no futuro, em especial ao setor do turismo que depende intrinsicamente do clima e do meio ambiente natural para seu desenvolvimento.

Com grande consenso todas as projeções demonstram aumento de temperatura variando de $3^{\circ} \mathrm{C}$ no Sul do Brasil a até $5^{\circ} \mathrm{C}$ no Norte/Nordeste. Dentro deste quadro, o turismo assim como outros setores importantes da economia brasileira (agricultura, pecuária, geração de energia etc.) terá que se adaptar ao novo clima. Desta forma os impactos podem ser minimizados.

Deve ser observado que as repercussões das mudanças climáticas e seus efeitos diretos e indiretos podem promover também mudanças de interesse dos agentes, rumo a atividades que aproveitem as oportunidades que oferecem os novos cenários, como a ampliação do turismo em áreas de preservação. Da mesma forma a promoção do turismo em áreas rurais e de interior poderá descongestionar progressivamente áreas mais vulneráveis, saturadas, frágeis e cuja sustentabilidade esteja condicionada às mudanças climáticas.

Não existe um conjunto de medidas de mitigação e adaptação únicas. Todo o sistema turístico pode e deve tomar medidas para reduzir as emissões de GEE associados a suas atividades. Para os turistas, a escolha de meios de transporte menos poluente, busca de produtos e atividades com pegada de carbono zero e a compensação de suas emissões quando fizer uso do transporte aéreo. Para os agentes, a promoção de produtos com períodos de estadia mais longos, destinos mais próximos ao mercado emissor e o desenvolvimento de produtos e atividades ecoeficientes. Na esfera da política pública, governos e comunidades devem buscar desenvolver um marco normativo que estimule a economia energética e programas de educação e conscientização do turista sobre o tema. No setor de transporte e alojamento turístico, a eficiência energética e hídrica tem sido a alternativa mais indicada.

Para alcançar tais objetivos o setor turístico deve centrar a sua ação fundamentada na aplicação de tecnologias e, na adaptação dos negócios e destinos turísticos às novas condições ambientais (a adaptação pode ser em termos de sazonalidade, diversificação da oferta, entre outros).

\section{REFERÊNCIAS}

Ambrizzi, T.; Artaxo, P. (2014). Aquecimento global, menos mito mais ciência. Disponível em: http://www.pbmc.coppe.ufri.br/pt/noticias/294- 
aquecimento-global- menos-mito-e-mais-ciencia. Acesso em 02 de setembro de 2014.

Ambrizi, T. (2015). Desenvolvimento, mudanças climáticas e turismo. Especialista consultado em julho de 2015.

Bardin, L. (2011). Análise de conteúdo. São Paulo: Edições 70, 229 p.

Brasil. Câmara dos Deputados. (2008). Mudanças climáticas: o turismo em busca da ecoeficiência. Brasília: Câmara dos Deputados, Edições Câmara, 2008. XX p. - (Série ação Parlamentar; n. 377).

Campos Filho, A.V. (2014). Turismo comunitário e mudanças climáticas. Especialista consultado em junho de 2014.

Carmo, R. L.; Silva, C. A. M. (2009). População em zonas costeiras e mudanças climáticas: redistribuição espacial e riscos. In: Hogan, D. J.; Marandola Jr. (Org.). População e mudança climática: dimensões humanas das mudanças ambientais globais. Campinas: Núcleo de Estudos de População; UNFPA, (1) 1, 137-158.

Conti, J.B. (2005). Considerações sobre as Mudanças Climáticas Globais. Revista do Departamento de Geografia. São Paulo, USP, (1)16, 7075.

Coriolano, L. N.; Lima, L. C. (2015). Turismo comunitário e mudanças climáticas. Especialista consultada em junho de 2015.

Cramer, J. (2000). Early warning: integrating ecoefficiency aspects into the product development process. Environmental Quality Management Winter, $1-10$.

Dolan, A. H.; Walker, I. J. (2004). Understanding vulnerability of coastal communities to climate change related risks. Journal of Coastal Research,
SI 39 (Proceedings of the 8th International Coastal Symposium), Itajaí, SC - Brazil.

Fernandes, K. (2011). Disponível em: https://noticias.uol.com.br/cotidiano/ultimas-noticias/2011/06/05/praias-no-ceara-devem-desaparecer-em-dez-anos-diz-estudo.htm\#fotoNav=4.

Acesso em 23 de maio de 2017.

Fitchett, J.M.; Grant, B.; Hoogendoorn, G. (2016). Climate change threats to two low-lying South African coastal towns: risks versus perceptions. South African Journal of Science, (1) 112, 5/6, may/june.

Frangialli, F. (2007). Turismo irá contribuir para soluções para a mudança climática global e a pobreza. Disponível em: www.medioambienteonline.com. Acesso em 20 de setembro de 2013.

Gossling, S. Et Al. (2005). The eco-efficiency of tourism. Ecological Economics, v. 54, p. 417- 434.

Grimm, I. J.; Prado, L. Giacomitti, R. B. Mendonça, F. A. (2013). Mudanças climáticas e o Turismo: desafios e possibilidades. Revista Brasileira de Climatologia, 8(11), julholdezembro.

Grimm, I.J. (2016). Mudanças climáticas e o turismo: estratégias de adaptação e mitigação. Tese (Doutorado) - Programa de Pós-Graduação em meio Ambiente e Desenvolvimento da Universidade Federal do Paraná. Curitiba, 250p.

Intergovernamental Panel On Climate Change IPCC. (2001). Grupo de Trabalho 2. Terceiro Relatório de Avaliação, Anexo B: Glossário de Termos.

. (2007). Climate change. Synthesis Report. Geneva.

(2013). "Resumen para responsables de políticas. En: Cambio Climático 2013: Bases físicas. Contribución del Grupo de trabajo I al Quinto Informe de Evaluación del Grupo Intergubernamental de Expertos sobre el Cambio Climático" 
[Stocker, T. F., D. Qin, G.-K. Plattner, M. Tignor, S. K. Allen, J. Boschung, A. Nauels, Y. Xia, V. Bex y P.M. Midgley (eds.)]. Cambridge University Press, Cambridge, Reino Unido y Nueva York, NY, Estados Unidos de América. Disponível em: http://www.ipcc.ch/pdf/assessmentport/ar5/wg1/WG1AR5 SPM brochure es.pdf.

Acesso em 21 de setembro de 2014.

(2014). Climate Change. Synthesis Report Summary for Policymakers. Disponível em: https://www.ipcc.ch/pdf/assessment-report/ar5/syr/AR5 SYR FINAL SPM.pdf. Acesso em junho de 2016.

Koumrouyan, A. Et Al. (2010). Projeções climáticas para o século XXI: IPCC AR4, IPCC AR5. São José dos Campos, São Paulo.

Kron, W. (2008). Coasts - The riskiest places on Earth. In: Smith, J. M. (Org.). Coastal Engineering. In: INTERNATIONAL CONFERENCE ON COASTAL ENGINEERING (ICCE, 2008), 31, Hamburg, Germany. Proceeding.

Maditinos, Z.; Vassiliadis, C. (2008). Crises and disasters in tourism industry: happen locally, affect globally. Management of International Business and Economics Systems, MIBES Conference 2008. Technological Institute of Larissa. School of Business and Economics. Larissa, Greece, 4-5 july, 2008, p. 67-76.

Marengo, J. A. (2007). Mudanças climáticas e eventos extremos no Brasil. Fundação Brasileira para o Desenvolvimento sustentável - FBDS, 76p.

. (2015). Desenvolvimento, mudanças climáticas e turismo. Especialista consultado em juIho de 2015.

Mello, C.; Mckeown, J.; Minninger, S. (2009). (Org.) Disaster Prevention in Tourism Perspectives on Climate Justice. Ecumenical Coalition on Tourism in cooperation with EED Tourism Watch, Germany.
Mendonça, F. (2007). Aquecimento global e suas manifestações regionais e locais. Revista Brasileira de Climatologia, 2, p. 71 - 86.

Moreno, A. (2010). Climate Change and Tourism Impacts and Vulnerability in Coastal Europe. Tese (Doutorado) - Maastricht University. Universitaire PERS. Disponível em: http://arno.unimaas.nl/show.cgi?fid=20143. Acesso em 17 de julho de 2014.

Moreira, C.J.E. (1986). Rainfall and flooding in the Guayas river basin and its effects on the incidence of malaria 1982-1985. Disasters, 10(2), p. 107-111.

Muehe, D \& Rosman, P.C.C. (2011). A orla Costeira da região metropolitana do Rio de Janeiro: impactos das mudanças climáticas sobre o meio físico. Disponível em: https://s3.amazonaws.com/tapajos/Megacidades/3 Orla.pdf.

Acesso em 03 de maio de 2017.

Nobre, C.A.; Sampaio, G.; Salazar, L. (2007). Mudanças climáticas e Amazônia. Ciência e Cultura, 59 (3), São Paulo, july/sept.

Oliveira, M. E. (2015). Desenvolvimento, mudanças climáticas e turismo. Especialista consultado em setembro de 2015.

Organizatión Mundial Del Turismo. (2007). De Davos a Bali: la contribución del turismo al reto del cambio climático. Davos, Suiza, 3 de octubre de 2007. Disponível em: http://sdt.unwto.org/sites/all/files/docpdf/ccbrochdavbalmembbgsp.pdf. Acesso em 10 de janeiro de 2017.

Organização Mundial Do Turismo/Pnuma/Omm. (2008). Cambio climático y turismo: Responder a los retos mundiales. Resumo. Disponível em: http://www.world-tourism.org/espanol/ index.htm . Acesso em 03 de junho de 2014.

Painel Brasileiro De Mudanças Climáticas PBMC. (2014). Contribuição do Grupo de TrabaIho 3 ao Primeiro Relatório de Avaliação Nacional 
do Painel Brasileiro de Mudanças Climáticas. Sumário Executivo do GT3. PBMC, Rio de Janeiro, Brasil, 24 p.

Peeters, P. Et Al. (2017). The eco-efficiency of to tourism. Disponível em: http://www.datasheets.tips/culture-and-the-arts/the-eco-efficiency-of-tourism/. Acesso em:

junho de 2017.

Rayamajhi, S. (2012). Tourism and Climate Change: A Study of the Perceptions of Stakeholders along the Annapurna Trekking Trail. Nepal Tourism and Development. Review 2, p. 60-86.

Redclift, M. R. (2015). Desenvolvimento, mudanças climáticas e turismo. Especialista consultado em setembro de 2015.

Rosman, P. (2007). As vulnerabilidades do litoral do Rio na mira da ciência. Disponível em: http://www.planeta.coppe.ufri.br/artigo.php?artigo=859. Acesso em 02 de agosto de 2015.

Santos, M. J. (2000). Mudanças Climáticas e o Planejamento Agrícola. In Sant'anna Neto, J. L. e Zavatini, J. A. (org.). Variabilidade e mudança climática: implicações Ambientais e Socioeconômicas. Maringá: Editora da Universidade Estadual de Maringá.

Scott, D.; de Freitas, C.R.; Matzarakis, A. (2009). Adaptation in the tourism and recreation sector. In: Mcgregor, G.R.; Burton, I.; Ebi, K. (Org.) Biometeorology for adaptation to climate variability and Chang, p. $171-194$.

Scott, D.; Gossling, S.; Hall, M. (2012). International tourism and climate change. Wiley Interdisciplinary Reviews: Climate Change, 3, p. 213-232, maio/jun.

Simpson, M.C., Gossling, S., Scott, D.; Hall, C.M.; Gladin, E. (2008). Climate Change Adaptation and Mitigation in the Tourism Sector: Frameworks, Tools and Practices. UNEP, University of Oxford, UNWTO, WMO: Paris, France, 158p.

Stern, N. (2006). Stern Review on the Economics of Climate Change. Cambridge University Press.
Viola, E. (2010). A Política Climática Global e o Brasil: 2005-2010. Revista tempo do mundoRTM, 2 (2), p. 81-117, ago.

Welzer, H. (2010). Guerras Climáticas: porque mataremos e seremos mortos no século 21. São Paulo: Geração editorial, 314 p.

Informações dos autores

\section{Isabel Jurema Grimm}

Doutora em Meio Ambiente e Desenvolvimento, pela UFPR (2016). Mestre em Desenvolvimento Regional pela FURB (Blumenau - 2010). Graduada em Turismo pela Universidade do Oeste de Paraná - UNIOESTE (Foz do Iguaçu - 1989). Especialista em Administração do Desenvolvimento da Atividade Turística em Núcleos Receptores pela USP - SÃO PAULO (1991) e Especialista em Didática e Metodologia de Ensino pela UNOPAR (Londrina - 1998). Curso de Administração Hoteleira em Mallorca - Espanha (1998). Trabalho na Secretaria de Turismo de Foz do Iguaçu (PR) no departamento de projetos e pesquisas. Ministrou aula no curso de Turismo na Universidade Federal do Paraná, foi professora superior pela FAMEC - Faculdade Metropolitana de Curitiba e da Faculdades Santa Amélia (Ponta Grossa). Atuou na Secretaria de Turismo de Pomerode (SC). Pesquisadora do Núcleo de pesquisa (NECOS) da UFPR\PR e do CEPES/ISAE. Pós doutoranda do PPG em Gestão Urbana da Pontifícia Universidade Católica do Paraná, junto ao projeto de pesquisa: Ecossocioeconomia Urbana e arranjos socioprodutivos, e autogestão comunitárias para o desenvolvimento territorial sustentável. Coordena o Programa de Pós-Graduação em Governança e Sustentabilidade do Instituto Superior em Administração e Economia ISAE (FGV). Trabalha com as linhas de pesquisa em Desenvolvimento Territorial, Cooperativismo, Ecossocieconomias, Turismo e Sustentabilidade.

Email: isabelgrimm@gmail.com

ORCID: https://orcid.org/0000-0003-0211-8048

\section{Liliane Cristine Schlemer Alcântara}

Pós-doutora em Ecossocioeconomia e Bem Viver pelo Programa de Pós-graduação em Gestão Urbana PPGTU/PUCPR. Doutora em Desenvolvimento Regional pela Universidade Regional de Blumenau PPGDR/FURB. Doutorado Sandwich no Instituto de Estudios Cooperativos de Mondragón Unibertsitatea (MU) - (LANKI) - Facultad de Humanidades y Ciencias de la Educación (HUHEZI). Mestre em Administração. 
Especialista em Programa de Apoio ao Ensino e à Pesquisa Científica e Tecnológica em Educação Profissional Integrada à Educação de Jovens e Adultos - PROEJA, Administração Rural e Metodologia e Didática do Ensino Superior. Graduada em Administração pela Sociedade Educacional Três de Maio (1987). Linhas de pesquisa em Desenvolvimento Regional: Desenvolvimento Territorial Sustentável, Educação para o Ecodesenvolvimento, Educação para o Cooperativismo, Ecossocioeconomia e Bem Viver (Buen Vivir). Pesquisadora dos Grupos de Pesquisa: Núcleo de Pesquisas Públicas (NPP/FRUB). Análise Ambiental e Ecodesenvolvimento (FURB/SC). Resiliência e Agricultura familiar na Amazônia e Núcleo de Ecossocioeconomia (NEcos) da UFPR/PR. Professora da Faculdade de Administração e Ciências Contábeis (FACC) UFMT -Universidade Federal de Mato Grosso. Professora colaboradora do Programa de Pós-graduação em Ciências Ambientais (PPGCA/UNEMAT).

Email: isabelgrimm@gmail.com

ORCID: https://orcid.org/0000-0001-8502-720X

\section{Carlos Alberto Cioce Sampaio}

Administrador/PUCSP, Mestre e Doutor em Planejamento e Gestão Organizacional para o Desenvolvimento Sustentável/UFSC, e Pós-doutorado em Ecossocioeconomia/UACH, Cooperativismo Empresarial/U.Mondragon e Ciências Ambientais/Washington State University (WSU). Pesquisador de Produtividade/CNPq. Coordenador (2016-2018) e Coordenador Adjunto (2012-2016) da Área de Ciências Ambientais/CAPES. Membro do Conselho Técnico Superior (CTC) ampliado/Capes entre 2016 - 2018. Membro do
Comitê Consultivo de Planejamento Urbano e Regional/Fundação de Amparo à Pesquisa do Paraná (F. Araucária). Realizou estágios com dois pesquisadores sêniors, Manfred Max-Neef (ganhador do Prêmio Nobel Alternativo) e Ignacy Sachs (um dos criadores do Eco-Desenvolvimento), além do estágio no Complexo Cooperativo de Mondragón, País Basco, exemplo paradigmático global de cooperativismo, 2009. Fulbright Foundation Scholar (EUA), 2015, Professor visitante do Centro Brasileiro de Estudos Contemporâneos da Escola Superior de Ciências Sociais de Paris, 1996, e do Centro de Estudos Ambientais da Universidade Austral do Chile (UACH, 2005. É professor do Programa de Pós-Graduação (PPG) em Desenvolvimento Regional/FURB, Gestão Ambiental /UP e Meio Ambiente e Desenvolvimento/UFPR. É pesquisador visitante do Laboratório de Processos Interpessoais/WSU e professor visitante no PPG em Desenvolvimento a Escala Humana e Economia Ecológica/UACh. Coordena o Núcleo de Ecossocioeconomia e em parceria Núcleo de Políticas Públicas. É pioneiro em pesquisas teóricas e empíricas sobre o tema Ecossocioeconomia, compreendendo Planejamento e Gestão Organizacional para o Desenvolvimento Territorial Sustentável, e Arranjos Políticos e Socioprodutivos de Base Territorial e Turismo de Base Comunitário na América Latina. Publicou cerca de 104 artigos em periódicos e 149 trabaIhos publicados em eventos nacionais e internacionais, além de 10 livros e 55 capítulos.

Email: carlos.cioce@gmail.com

ORCID: https://orcid.org/0000-0002-0664-0266 